\title{
Placing HIV beyond the metropolis: Risks, mobilities, and health promotion among gay men in the Halifax, Nova Scotia region
}

Nathaniel M. Lewis

School of Geography, University of Southampton

Research on HIV/AIDS among gay men in North America has departed from pure disease diffusion models to consider the social and environmental contexts where transmission may take place. Most of this work, however, focuses on large metropolitan areas and operationalizes the concept of place with only some degree of nuance. Large cities - and the bars, bathhouses, and gay villages within them-are often treated as containers of attributes that contribute to and concretize HIV risk. This article therefore seeks to apply a critical, ecological conception of place to understanding HIV risk, education, and prevention among gay men in the small city-region of Halifax, Nova Scotia. Using in-depth interviews with HIV/AIDS-related service providers and self-identified gay men, the study highlights four dynamics of HIV risk potentially affecting gay men in smaller cities and rural areas: (1) institutional ambivalence toward HIV education and messaging, (2) narrow conceptions of risk, (3) migrations into unfamiliar social and sexual environments, and (4) social and structural barriers to health service utilization.

Keywords: HIV/AIDS, gay men, Nova Scotia, sexual health, health promotion

\section{Situer le VIH au-delà de la métropole : les risques, les mobilités, et la promotion de la santé chez les hommes gais dans la région d'Halifax, Nouvelle-Écosse}

Les travaux de recherche menés sur le VIH/sida chez les hommes gais en Amérique du Nord ont rompu avec les modèles limités à la diffusion de la maladie afin de tenir compte davantage des contextes sociaux et environnementaux de transmissions possibles. Cependant, ce corpus scientifique est consacré aux grandes régions métropolitaines et applique la notion de lieu de façon peu nuancée. Les grandes villes, les bars, les saunas, et les villages gais qu'on y retrouve sont souvent désignés comme des milieux caractérisés par les attributs qui favorisent et concrétisent le risque de transmission du VIH. S'appuyant sur une conception écologique critique du lieu, cet article a pour objet de mettre en lumiere le risque, les programmes d'éducation et la prévention en matière de VIH chez les hommes gais à Halifax, Nouvelle-Écosse, une villerégion de petite taille. Au moyen d'entrevues réalisées auprès de fournisseurs de services spécialisés dans le $\mathrm{VIH} /$ sida et auprès d'hommes s'étant déclarés gais, l'étude montre combien les dynamiques sociales et institutionnelles particulières ont une influence sur la façon dont les gais de la région conçoivent et se préoccupent du risque de transmission du VIH. Leurs récits mettent en évidence l'ambivalence institutionnelle envers les programmes d'éducation et la communication de messages portant sur le VIH, les négociations individuelles complexes entourant l'identité sexuelle et l'acte sexuel proprement dit, et les obstacles à l'accès aux services de santé sexuelle. II en ressort un agencement particulier de discours sur le VIH et des risques potentiels que courent les hommes gais dans les petites villes et les autres régions périphériques du Canada. Mots clés : VIH/sida, hommes gais, Nouvelle-Écosse, santé sexuelle, promotion de la santé

Correspondence to/Adresse de correspondance: Nathaniel M. Lewis, School of Geography, University of Southampton, 2508 Shackleton Building, University Road, Southampton, UK SO17 1BJ. Email/Courriel: n.m.lewis@soton.ac.uk

The Canadian Geographer / Le Géographe canadien 2015, xx(xx): 1-10 


\section{Introduction}

Emerging research on the human immunodeficiency virus and acquired immune deficiency syndrome (HIV/AIDS) among gay men ${ }^{1}$ in North America has begun to link HIV risk with particular geographic spaces. The metropolitan-centred studies that comprise the majority of this research focus typically on gay neighbourhoods, bars, bathhouses, cruising areas, and other places where HIV risk behaviours (e.g., substance use, unprotected sex, sex with multiple partners) are thought to be encouraged or facilitated (Binson et al. 2001; Carpiano et al. 2011; Egan et al. 2011; Kelly and Carpiano 2012; Buttram and Kurtz 2013). Studies on rural gay men, in contrast, tend to connect risk behaviours to negative states of mind caused by "rigid and morally traditional standards of sexuality leading to secretive lives and feelings of isolation" (Williams et al. 2005,48 ) or to separation from ostensible centres of gay culture where preventative health promotion efforts have been more concentrated (Bowen et al. 2007). While both urban and rural studies suggest associations between location and particular risk behaviours, the actual social and institutional processes through which places influence HIV risk among gay-identified men and other men who have sex with men (MSM) are less well understood, particularly in small cities and mixed rural-urban areas (however, see Lovell and Rosenberg 2011). As an alternative to a purely epidemiological approach focused on polygons of statistical attributes (Brown and Knopp 2006), gay men's health researchers have also begun to examine the relationships between HIV/AIDS and place-based ecologies (McLeroy et al. 1988) that include social networks, health discourses, and health promotion regimes (M. Brown 1997; T. Brown 2000; Brown and Knopp 2014; Lewis 2014a).

The following qualitative, narrative-based study of the Halifax, Nova Scotia region explores the more nuanced relationships between place, networks, institutions, and men's experiences of HIV/AIDS in a place that qualifies neither as metropolitan nor fully rural. Comprising the city of Halifax (population 130,000$)$, the city of Dartmouth $(65,000)$, and

\footnotetext{
${ }^{1}$ The term gay is used here to reflect the self-ascribed identities of the individual men interviewed in this article, and is used as a proxy to describe men who have sex with men, or MSM (though they may self-identify as bisexual or straight).
}

several smaller communities under 15,000 in population (Statistics Canada 2011), the region represents a kind of in-between place not typically included in the research on gay men and HIV/AIDS. Using interviews with both HIV/AIDS service providers and gay-identified men, this article offers accounts of HIV risk and prevention that extend beyond binary frameworks of rurality, stigma, and isolation-or alternately, urbanity, the gay scene, and risk exposure. After a brief literature review and description of methods, four subsequent sections discuss the evolution of HIV/AIDS education and messaging in Nova Scotia, participants' interpretations of these messages, the role of mobility in their sexual life-geographies, and the ways in which local and regional health care institutions seek to manage the complex regional geography of HIV/AIDS.

\section{Sexuality, place, and gay men's health}

Understanding HIV risk and prevention in settings like the Halifax region requires complicating the concepts of urban and rural. The literature on rural gay and lesbian lives offers one productive entrée. On the one hand, rural areas have been cast as places where non-heterosexual identities are invisible, where the heteronormative influences of the state go uncontested, and where one might go to overcome same-sex attraction (Bell and Valentine 1995; Bell 2000). On the other, the incomplete overlap of gay culture with urbanity (Herring 2010) means that rural places ranging from country festivals to private homes can also emerge as distinctive, even psychologically restorative alternatives to urban gay life (Bell and Valentine 1995; Bell 2000; Gorman-Murray et al. 2008). Concepts of rural and regional gay life are often contradictory. The idealized notion of a rugged, purely gay masculinity, for example, can distract from the fact that gay men are still often stigmatized and marginalized in rural areas (Bell 2000).

Gay men's health is affected not only by simple urbanity and rurality, but also by the multi-scaled institutions and networks that assemble in and across places (T. Brown 2000; Del Casino 2007; M. Brown 2009). Michael Brown (1995) and Tim Brown (2000) have both argued, for example, that public health authorities use the idea of "at-risk" 
populations (e.g., gay men) and "high-risk" places (e.g., bathhouses) to separate risky others from the general population and to make HIV/AIDS a calculable threat that can be linked statistically to particular people and places. Public health messaging has thus tended to target urban, out gay men who ostensibly can be convinced to shift their sex behaviours and habits (Zablotska et al. 2011). In contrast, men who fall outside these norms and places are sometimes considered unreachable or problematic (Del Casino 2007; M. Brown 2009). More importantly, the gay male subjects targeted by health institutions are not necessarily fixed in place at all. Geographers have long suggested that gay men and other sexual minority individuals move frequently throughout the life course to come out, improve their health and well-being, and negotiate variegated landscapes of stigma and inclusion (Knopp 2004; Gorman-Murray 2007; Lewis 2012, 2014a, 2014b).

At first glance, the Halifax region fits some of the stereotypes employed in epidemiological studies of rural gay men and HIV/AIDS. At the national level, it sits within an Atlantic Canadian periphery described as resource-dependent, gender-normative, and organized around the kinship of heteronormative extended families and communities (Tomblin 1995; Bulman 2005; Moreira 2012). Locally, the midsized service hub of Halifax is joined both politically and discursively with a 2,000 square mile $(5,000$ square kilometer) area known as the Halifax Regional Municipality (HRM). The area comprises dozens of small, agricultural, and often religious and conservative towns and villages from which the city of Halifax draws residents, voters, and commuters (see Morrill et al. 1999). At the same time, recent projects have documented the history of a vibrant gay life within Halifax's maritime industry (Moore 2011) and the city is now marketed as a gay tourist destination with its own local scene (Destination Halifax 2013). Gay and lesbian activists have also had many successes in the Halifax region, creating a dense local meshwork of HIV/AIDS prevention efforts in the 1980s (Plumb 2005) and achieving several gay rights victories (e.g., the first successful Canadian same-sex partner pensions benefits case) in the 1990s (Boutilier 1998; Lewis 2015). Despite these early advances, the health of gay men in Nova Scotia has often been sidelined in a geographic Catch-22. While gay men are overrepresented in the province's HIV and syphilis epidemics (see Table 1 ), ${ }^{2}$ national-level disease surveillance concerning gay men (e.g., The M-Track system) often bypasses Atlantic Canada altogether (Challacombe 2013) and Nova Scotia's sexual health services are not as accessible or advanced as those in the largest cities (Lewis et al., 2013). As the forthcoming narratives show, communities and institutions in Nova Scotia have also cast gay men's health and HIV/AIDS as politically controversial and peripheral to "mainstream" health issues.

\section{Methods}

This study employs in-depth semi-structured interviews with similarly sized groups of HIV/AIDS service providers (nine) and gay-identified men (seven) within Halifax County and Colchester County, Nova Scotia. Two participants chose to speak in both capacities and were included in both groups. The service provider group, which included HIV nurses, HIV/AIDS service organization (ASO) directors, outreach workers, and policy specialists, was recruited through personal or online contact between July 2012 and January 2013. The gay male participants, including five HIV-negative and two HIV-positive men, ranged in age from late twenties to early sixties and were recruited through provider postings or referrals. Interviews lasted 30-75 minutes each and were transcribed in full. While providers were asked about their professional experiences in HIV-related health promotion, the individual men were asked to discuss their understandings of HIV risk in the context of their broader life histories in Nova Scotia. Following a constructivist grounded theory approach (Charmaz 2006), the two sets of interviews were coded iteratively and then triangulated to verify the four relevant themes (Yin 2003).

"Let's not talk about it 'cause it's not a problem": HIV and sexual health messaging in Nova Scotia

In the 1980s and 1990s, HIV/AIDS cases and deaths in Canada were concentrated in the few largest

\footnotetext{
${ }^{2}$ For syphilis, exposure categories are not reported, but most male cases have been linked to sex with other men (LeBlanc 2013). For both HIV and syphilis, because cases are reported by the province where testing is done, there is likely some underreporting due to Nova Scotians testing outside of Nova Scotia (see also Lewis et al. 2013).
} 
Table 1

Reported Cases of HIV and Syphilis, Nova Scotia, \% Male (HIV and Syphilis) and \% MSM Exposure Category (HIV Only), 2008-2012

\begin{tabular}{lrrrrr}
\hline & 2008 & 2009 & 2010 & 2011 & 2012 \\
\hline HIV & 14 & 14 & 15 & 15 & 17 \\
$\%$ Male & 79 & 79 & - & 88 & 100 \\
$\%$ MSM & 46 & 36 & - & 63 & 77 \\
Syphilis & 12 & 24 & 27 & 36 & 63 \\
Male & 100 & 96 & 100 & 100 & 98
\end{tabular}

Sources: NSHW 2013, 2012, 2011 ; NSHPP 2010, 2009.

cities. Although the early impact of the HIV epidemic in Nova Scotia generated the creation of two ASOs in Halifax in the 1990s (Plumb 2005), its overall visibility paled in comparison to places such as Vancouver, where some neighbourhoods (e.g., the West End, Yaletown) witnessed hundreds of deaths of gay men in a single year (Brown 1997). Two providers surmised that in Nova Scotia, the relative lack of public exposure for HIV had created both a general lack of awareness and-in some locales-a more purposeful denial of the risk of HIV/AIDS.

\begin{abstract}
My colleague ... she went [to Vancouver] and she's like "God, you go on the subway ... there's posters for [HIV] testing all over the place." Like you don't see that here ... it's not on our radar. (HIV policy advisor, Halifax County)
\end{abstract}

The biggest push-pull typically from our experience and history in working in rural communities is about "let's not talk about it 'cause it's not a problem here," because [HIV-positive people], whoever they are, are not here ... and I'm not them and thus I'm not at risk so let's just not do that. (ASO director, Halifax County)

Several interviewees felt that the perception of HIV/AIDS as a rare disease in Nova Scotia, while rooted partially in statistics, was also perpetuated purposefully by government and health care institutions. Public health authorities have frequently sought to create moral panic over HIV/AIDS to encourage health behaviours such as safer sex and HIV testing among gay men (T. Brown 2000). Institutions in the Halifax region, however, have often seemed focused on preventing panic and anxiety in populations and health care systems unprepared to acknowledge the realities of HIV/ AIDS in Canada. In Nova Scotia, an aging population profile and the fiscal constraints of a havenot province (Lecours and Beland 2010), have- according to some interviewees-resulted in a health education system where instructors are significantly older than their students, often lack a health background, and may be uncomfortable discussing HIV/AIDS or sexual health (see also Langille et al. 2001). Providers suggested that high school teachers were not always reliable sources of HIV information, particularly for gay men and MSM. "I think a lot of teachers are well intended, but a lot of them are not as well equipped to come in and teach sexuality or they're not comfortable with [HIV or gay identities] depending on their backgrounds" (HIV policy advisor, Halifax County). "We still have teachers," another said, "that are supposed to be the liaison for [LGBT] students but they ... don't understand what [LGBT] students are going through" (ASO director, Colchester County).

In some cases, public schools have also exerted a more pronounced biopower over students in order to prevent panic and controversy within families and communities (M. Brown 2009). One example was the response of public schools to the introduction of Sex?-A Healthy Sexuality Resource in Nova Scotia middle and high schools in 2004 (HSWG 2006). The so-called "sex book," which included sections on homosexuality and STIs, was banned by some school boards and within other boards distributed only to students who had acquired permission from their parents to view it (Witte 2004). Several schools also prohibited gay straight alliances (GSAs) prior to a 2012 ruling by the Nova Scotia Minister of Education that the formation of GSAs must be permitted unequivocally by school administrators (Hinchliffe 2012). One of the interviewees (Tom, 30s, Colchester County), who had worked as a health teacher in a public high school, recalled being summoned into the principal's office for "pushing the gay agenda" after answering a female student's question about anal sex. "We had 720 kids in our school and he told me that we had no gay students," he said.

The stigmatization of both HIV/AIDS and homosexuality has also influenced informal knowledge exchange within the gay community itself. Previous research has shown that the diffusion of anti-gay and anti-HIV stigma through homes and schools, combined with internalized homophobia and trauma surrounding coming out, can decrease gay men's willingness to acknowledge HIV risk (see Lewis 2009, 2014b). One provider confirmed that men's experiences in local schools and workplaces had 
rendered HIV/AIDS mostly unspeakable in the Halifax gay community:

I think there are huge undertones among gay men talking about HIV/AIDS. And I think there's a lot of stigma, I think there's fear, I think there's just "oh, I wore that [discrimination] just trying to come out," right? ... Like I know if I go down to [local gay bar], a lot of people would choose not to communicate with me, which is totally okay because they'd have to explain why do you know [provider's name] right? ... there's a reason why they would know me. (ASO director, Halifax County)

Interviewees described their fear of being associated with HIV/AIDS if they chose to acknowledge or discuss it: "Within the gay community in Toronto and the big cities, there's a lot more talk about HIV and there's a lot more acceptance, and here it's just not the case" (health outreach worker, Halifax County). Consequently, men living in smaller cities and rural areas may not only have reduced access to HIV-related information, but feel compelled to perpetuate the culture of silence around HIV/AIDS.

\section{Because the information is not so available, that there is the unknown of it and the non-education, people don't ask questions 'cause they're so afraid of it ... it's that little elephant in the room that no one really discusses unless someone's courageous enough ... I don't know what the stages [of HIV] are. I don't know what medicine's like these days, legally I don't know what happens [after disclosure]. (Jason, 20s, Halifax County, HIV-negative)}

In this way, the discursive erasure of HIV/AIDS in Nova Scotia both perpetuates stigma and maintains potentially narrow conceptualizations of HIV risk among gay men living there.

\section{"A little more free": From knowledge to behaviour}

Discourses of HIV absence or rarity may lead some men to take calculated risks such as having sex without a condom, also known as barebacking (see Dean 2009). One interviewee (Mark, 30s, Halifax County, HIV-negative), referring to statistics for diagnosed AIDS cases rather than the diagnosed or undiagnosed HIV cases from which most new infections are transmitted, said, "You know, you get a little bit comfortable I guess maybe, and after [having unprotected sex] you realize okay maybe it's not so bad that there are only 300 and some [AIDS cases] registered in Nova Scotia, not just Halifax.” A second interviewee also reported feeling a similar tension between his awareness of risk and a sense of assurance that he would not be infected: "I was focused enough to know when to get a test but I wasn't necessarily consistent that way, you know ... I was saying, 'oh you know we have a lower population of [HIV] so I'm fine. I can be, you know, a little more free'” (Jason, 20s, Halifax County, HIVnegative).

Gay men situated in smaller cities and rural areas may also choose to seek out sexual encounters online because they lack access to gay venues or do not want to be publicly out (see Williams et al. 2005; Horvath et al. 2006). In previous large-scale studies and meta-analyses (e.g., Bolding et al. 2005; Liau et al. 2006), gay men who met partners online were reported as more likely to have an STI or to have unprotected sex than those who met partners in person. Such findings, however, tend to be based on groups of urban gay men who are situated in higherprevalence locales, have access to a greater density of potential partners, and are sometimes sampled from networks and sites associated specifically with cultures of barebacking or "party and play" (i.e., sex under the influence of drugs). While exposure to HIV risk may therefore be categorically lower for rurally situated men, the transitory nature of encounters set up online could reduce opportunities for negotiating safer sex among partners who might already be disinclined to discuss sexual health (Horvath et al. 2006).

You know a lot of people, depending on where you are, I mean some people feel like they can't come out so they're doing things that may be riskier because perhaps they don't even want to really talk about it ... if they're not talking, they're not comfortable talking to partners or going and getting condoms ... I suppose you're doing things a little bit more spur of the moment that you hadn't planned on. (HIV nurse \#1, Halifax County)

One ASO in the region is attempting to bridge gaps in sexual knowledge health by creating profiles on online cruising sites where men can chat with a trained sexual health counsellor. The outreach worker administering the profiles noted that about 50 percent of the questions came from men outside Halifax or Dartmouth and that 80 percent listed 
their sexual orientation as bisexual or straight, suggesting that the at-risk population extends well beyond the out gay men traditionally targeted in public health campaigns (T. Brown 2000; Zablotska et al. 2011). In addition, men's online sexual networking to connect across a dispersed set of cities and towns suggests that risks are often encountered beyond one's immediate geographic context.

\section{"It was like fantasy land": Mobilities and risk encounters}

To date, most studies of HIV/AIDS and mobility in North America have focused on the return migrations of HIV-positive men to non-epicentre regions following diagnosis (Cohn et al. 1994; Ellis and Muschkin 1996) or effects of relocation on HIVpositive patients' adherence to antiretroviral treatment (Lima et al. 2009). In contrast, relatively little work examines relationships between mobility and risk among the uninfected. Emerging work on the health implications of internal and international migration, however, suggests that the stress and social displacement that occurs with relocation may lead to increases in substance use, unprotected sex, and other risk factors for HIV/AIDS. Affected groups of men include migrant and temporary workers (Kalipeni et al. 2003; Winett et al. 2011), ${ }^{3}$ but also gay men who move to escape homophobia, come out, or engage in sexual exploration (Bianchi et al. 2007; Lewis 2014b). For men situated in rural areas of Nova Scotia, intra-regional trips to Halifax may constitute first encounters with visibly gay meeting places, the potential for multiple partners, increased access to drugs, and overall higher HIV and STI rates. One provider, referencing the recent syphilis outbreak, described the mobilities-as-risk scenario:

If I'm looking at the information we're collecting on syphilis right now ... what we're seeing is people from rural areas and outside of Halifax flocking to this urban area because there are no [gay bars] close to them. So they flock here ... and they may not be out or they may have you know pent up energy or whatever

\footnotetext{
${ }^{3}$ Interestingly, some providers observed a similar trend of displacement and use of sex workers among men leaving declining industries (e.g., fishing, mining) and depressed economies in Nova Scotia to work in the Alberta oil industry.
}

... they're going back and they're living their lives whether that's gay relationships or married to the opposite gender and potentially the spread [of syphilis]. (youth worker, Halifax County)

One of the men interviewed observed similar rural-to-urban mobilities in his own experiences online: "I had never [posted an online ad] before ... anyway it was just wild. I'll never forget waking up that morning to 129 emails after posting it the night before ... a lot [from] smaller little communities: 'Oh I get to Halifax all the time, oh I go there on business, I'm travelling there next weekend'" (Mark, 30s, Halifax County, HIV-negative).

Longer-term migrations from the Halifax region to other cities in Canada may also shape local men's risk contexts. Two providers discussed clients who had moved to larger cities from Nova Scotia and then returned to Halifax after contracting HIV, mirroring studies on both the potential stressors and health risks of moving to an urban gay community (Egan et al. 2011; Lewis 2012, 2014b) and the tendency to return home after becoming HIV-positive (Cohn et al. 1994; Ellis and Muschkin 1996).

I've had many conversations with ... gay men that might be around 30, 32 [years] in age, who have spent a number of years ... in the Toronto, Vancouver area, who talk about the minute they got there ... it was like fantasy land, right? And they took every advantage they could of course and nothing wrong with that, but we're not at all prepared for the emotions, the responsibilities or any of that associated with it. (ASO director, Halifax County)

Well certainly young guys who went to big cities and encountered a whole other realm and level of party scene, or gay party scene ... and also going, moving forward with the belief ... that really HIV is okay, it's not a big deal anymore, and that they don't have to be super conscious or careful and then they ended up with HIV ... and so that's about those self-care tools and that ability. (LGBT health liaison, Halifax County)

Other mobilities, however, may be temporary and recreational, what one provider described as "[to] go away to Toronto or Montreal and totally let loose, and totally go crazy ... in terms of having sex" (ASO outreach worker, Halifax County). One interviewee described going to other Canadian cities for work while living a straight life at home: "Whenever 
I would go away to a conference," he said, "I could feel myself transforming into this other person within me ... and if I was landing in Toronto, or Montreal, or Vancouver ... before I would even get to the hotel, I would actually head to the steam bath ... it was, you know, one after another ... if somebody said 'no, I don't really like to [use condoms],' then I would go anyway" (Richard, 60s, Colchester County, HIV-positive). In this sense, the more urgent nature of sexual encounters away from home or away from the closet, particularly in unfamiliar settings, can also lead to riskier behaviour (also see Lewis 2014a).

\section{"Those six degrees of separation are like two":} Anonymity and sexual health services

The uptake of sexual health services among gay men in the Halifax region is animated by many of the same social dynamics that have shaped their identities, self-concepts, and life-worlds. Almost half of the interviewees in both the individual and service provider groups used the phrase, "the six degrees of separation" to describe the gaze mediating health-seeking behaviours in localized family and community contexts. "Nova Scotia has big, old families," one provider said, “... in Halifax and outside of Halifax ... everybody's connected to everybody. You know, those six degrees of separation are like two" (LGBT health coordinator, Halifax County). Even in Halifax, said one nurse, "People ... don't want to walk into [the sexual health clinic] 'cause ... they think well if I walk in there everybody will know why I'm there" (HIV nurse \#2, Halifax County).

In outlying towns, the social disincentives to being tested can become amplified. Since anonymous HIV testing (AHT) is not available outside the Halifax city centre, potential clients may be concerned about having their name attached to an HIV test and the possibility of knowing the individuals handling the test (see Lewis et al. 2013): "Some people ... they'll even say ... I don't want anybody in the lab to know my name 'cause, you know, my neighbour works in the lab" (HIV nurse \#2, Halifax County). The same social bonds that may build community in small places can therefore become intrusive and oppressive for gay men who do not want to disclose their sexual identity or the need to be tested. One interviewee reflected on getting tested in his small town: "One [nurse] actually ... she said, 'oh why do you need to get tested all the time?' I mean a lot of them know my family and 'cause we're a fairly well-known family in the town" (Tom, 30s, Colchester County, HIV-negative). Moreover, the Nova Scotia Department of Health and Wellness has not implemented rapid point-of-care (POC) testing, which provides counselling, testing, and delivery of results within a single 30-45 minute period. Consequently, clients traveling to be tested at the single AHT site in Halifax would have to repeat the trip one week later to receive their test results (Lewis et al., 2013). According to one provider, these disincentives can be enough to discourage testing altogether:

I mean we have people drive all the way from wherever to just get anonymously tested here, and that's if they can even wrap their head around the thought of doing it ... or [they would] rather stay in denial and [they will] stay [at home]. You know even if there is that inkling like "I think I'm at risk, I know I'm at risk," versus actually acting on it. (ASO director, Halifax County)

An additional barrier to being tested in smaller communities is the perceived social impact of learning one's HIV status, especially if it is positive. Although the fear factor in HIV testing is well documented among gay men generally (e.g., Kellerman et al. 2002), those living in small and rural regions may perceive less control over disclosing their status.

And that's understandable ... the not wanting to know ... 'cause what would they do if, you know, 'cause again in a smaller city, you know, would everybody know, would they be shunned, would ... their family not want to speak to them anymore? (HIV nurse \#1, Halifax County)

People are terrified of other people finding out, you know they go on a date, they don't want to tell the other person that they're HIV positive for numerous reasons, but one of the big ones is who are they going to tell? Who's that person going to tell? (LGBT health coordinator, Halifax County)

As the narratives show, the same insularity that might lead communities to cordon themselves off from perceived social threats associated with gay men's health (e.g., public HIV prevention campaigns, gay-related sexual health education in schools) also maintains the invisibility of gay men in the health care system by creating a fear of service utilization. 


\section{Conclusions}

The ecological account of place adopted here demonstrates the distinct risk contexts and health promotion challenges for gay men living in a smaller city-region and challenges the more containerized conceptions of place often adopted within HIV/ AIDS discourses. While Nova Scotia still tends to be framed as a closed, peripheral place in terms of HIV/ AIDS diffusion (Bulman 2005) and understandings of Canada more generally (Tomblin 1995; Moreira 2012), men's personal narratives show that the epidemic permeates their lives in complex, sometimes unexpected ways. Their accounts reveal the relative silence over both gay men's sexualities and $\mathrm{HIV} /$ sexual health in the region, resulting potentially in both a lack of self-care tools and the internalization of anti-gay and anti-HIV stigma among men living there. Consequently, some may travel to locales where risk becomes amplified in terms of both the local epidemiology and their own abilities to negotiate the specific sexual environments and scenarios encountered. For smaller provinces and regions, HIV risk for gay men needs to be understood through analysis of their communities, mobilities, service infrastructures, and the discourses and institutions that influence all of these.

The results also have implications for the study of HIV/AIDS amidst a changing landscape of STI epidemics and interventions in Canada. Rates of syphilis have spiked in Halifax and other outlying areas of Canada in the past five years (LeBlanc 2013, see Table 1), and the past experience of towns such as Conception Bay, Newfoundland, shows that regions with previously limited exposure to HIV/ AIDS can suddenly become key sites of the epidemic (Ryan 1998). Yet even amidst a seemingly growing need for HIV/STI prevention strategies in diverse geographic contexts, some public health practitioners have declared that prevention has failed and that resources should be devoted to "treatment as prevention" (e.g., high-volume testing and immediate antiretroviral therapy for those infected) in highest-risk (e.g., street-involved) populations living in large cities (Montaner et al. 2011). Such an approach misses particular places and individuals (e.g., gay men in smaller cities and rural areas) who may encounter risk in less obvious ways. Research on HIV/AIDS in Canada therefore must also examine critically how gay men's health is constructed in different places. While health care institutions in the largest cities often frame gay men as overtly medicalized subjects in need of regulation (M. Brown 1995, 2009), places that are less comfortable with gay identities may be hesitant to identify them as an at-risk population deserving of public health resources. For smaller city-regions such as Halifax, further research is therefore needed to build on a "prevention as prevention" approach aimed at destigmatizing HIV/AIDS, accepting and educating gay men as sexual beings and community members, and preparing them for a variety of risk contexts across place.

\section{References}

Bell, D. 2000. Farm boys and wild men: Rurality, masculinity, and homosexuality. Rural Sociology 65(4): 547-561.

Bell, D., and G. Valentine. 1995. Queer country: Rural lesbian and gay lives. Journal of Rural Studies 11(2): 113-122.

Bianchi, F., C. Reisen, M. C. Zea, P. J. Poppen, M. G. Shedlin, and M. M. Penha. 2007. The sexual experiences of Latino men who have sex with men who migrated to a gay epicentre in the U.S.A. Culture, Health \& Sexuality 9(5): 505-518.

Binson, D., W. J. Woods, L. Pollack, J. Paul, R. Stall, and J. A. Catania. 2001. Differential HIV risk in bathhouses and public cruising areas. American Journal of Public Health 91(9): 14821486.

Bolding, G., M. Davis, G. Hart, L. Sherr, and J. Elford. 2005. Gay men who look for sex on the Internet: Is there more HIV/STI risk with online partners? AIDS 19(9): 961-968.

Boutilier, R. 1998. Nova Scotia leads the way. Wayves June: 1.

Bowen, A. M., K. Horvath, and M. L. Williams. 2007. A randomized control trial of Internet-delivered HIV prevention targeting rural MSM. Health Education Research 22(1): 120-127.

Brown, M. 1997. RePlacing Citizenship: AIDS activism and radical democracy. New York: Guilford Press.

—. 2009. 2008 Urban Geography Plenary Lecture. Public health as urban politics, urban geography: Venereal biopower in Seattle, 1943-1983. Urban Geography 30(1): 1-29.

Brown, M., and L. Knopp. 2014. The birth of the (gay) clinic. Health \& Place 28: 99-108.

- 2006. Places or polygons? Governmentality, scale, and the Census in The Gay and Lesbian Atlas. Population, Place and Space 12: 223-242.

Brown, T. 2000. AIDS, risk and social governance. Social Science \& Medicine 50: 1273-1284.

Bulman, D. 2005. A constructivist approach to HIV/AIDS education for women within the Maritime Provinces of Canada. International Journal of Lifelong Education 24(6): 475-487.

Buttram, M., and S. Kurtz. 2013. Risk and protective factors associated with gay neighbourhood residence. American Journal of Men's Health 7(2): 110-118.

Carpiano, R. M., B. C. Kelly, A. Easterbrook, and J. T. Parsons. 2011. Community drug use among gay men: The role of neighborhoods and networks. Journal of Health and Social Behavior 52(1): 74-90.

Challacombe, L. 2013. The epidemiology of HIV in gay men and other men who have sex with men (fact sheet). Toronto: 
CATIE. http://www.catie.ca/en/fact-sheets/epidemiology/ epidemiology-hiv-gay-men-and-other-men-who-have-sexmen.

Charmaz, K. 2006. Constructing grounded theory: A practical guide through qualitative analysis. London: Sage Publications.

Dean, T. 2009. Unlimited intimacy: Reflections on the subculture of barebacking. Chicago: University of Chicago Press.

Destination Halifax. 2013. Halifax: Find yourself out east. http:// www.destinationhalifax.com/rainbow.

Egan, J., V. Frye, S. Kurtz, C. Latkin, M. Chen, K. Tobin, C. Yang, and B. Koblin. 2011. Migration, neighborhoods, and networks: Approaches to understanding how urban environmental conditions affect syndemic adverse health outcomes among gay, bisexual, and other men who have sex with men. AIDS and Behaviour 15(1): S35-S50.

Ellis, M., and C. Muschkin. 1996. Migration of persons with AIDSA search for support from elderly parents? Social Science \& Medicine 43(7): 1109-1118.

Gorman-Murray, A. 2007. Rethinking queer migration through the body. Social \& Cultural Geography 8(1): 105-121.

Gorman-Murray, A., G. Waitt, and C. Gibson. 2008. A Queer Country? A case study of the politics of gay/lesbian belonging in an Australian country town. Australian Geographer 39(2): 171-191.

Herring, S. 2010. Another country: Queer anti-urbanism. New York: New York University Press.

Hinchliffe, A. 2012. Gay/straight alliance group to promote awareness. The Advance, March 13. http://www.theadvance. ca/Living/Education/2012-03-13/article-2925386/Gaystraight-alliance-group-to-promote-awareness.

Horvath, K. J., A. M. Bowen, and M. L. Williams. 2006. Virtual and physical venues as contexts for HIV risk among rural men who have sex with men. Health Psychology 25(2): 237-242.

HSWG (Healthy Sexuality Working Group). 2006. Sex?-A health sexuality resource. Halifax, NS: Nova Scotia Department of Health Promotion and Protection.

Kalipeni, E., Craddock, S., Oppong, J. R., and J. Ghosh. 2003. HIV and AIDS in Africa: Beyond epidemiology. London: WileyBlackwell.

Kellerman, S. E., J. S. Lehman, A. Lansky, M. R. Stevens, F. M. Hecht, A. B. Bindman, and P. M. Wortley. 2002. HIV testing within atrisk populations in the United States and the reasons for seeking or avoiding HIV testing. Journal of Acquired Immune Deficiency Syndromes 31(2): 202-210.

Kelly, B. C., R. M. Carpiano, A. Easterbrook, and J. T. Parsons. 2012. Sex and the community: The implications of neighbourhoods and social network for sexual risk behaviours among urban gay men. Sociology of Health \& Illness 34(7): 1085-1102.

Knopp, L. 2004. Ontologies of place, placelessness, and movement: Queer quests for identity and their impacts on contemporary geographic thought. Gender, Place \& Culture 11(1): 121-134.

Langille, D., D. MacKinnon, E. Marshall, and J. Graham. 2001. So many bricks in the wall: Young women in Nova Scotia speak about barriers to school-based sexual health education. Sex Education 1(3): 245-257.

LeBlanc, M.-A. 2013. What the syph is going on? Responding to syphilis outbreaks in Canada. CATIE Prevention in Focus, Spring. http://www.catie.ca/en/pif/spring-2013/what-syphgoing-responding-syphilis-outbreaks-canada.

Lecours, A., and D. Beland. 2010. Federalism and fiscal policy: The politics of equalization in Canada. Publius 40(4): 569-596.
Lewis, N. M. 2009. Mental health in sexual minorities: Recent indicators, trends, and their relationships to place in North America and Europe. Health \& Place 15: 1029-1045.

- 2012. Remapping disclosure: Gay men's segmented journeys of moving out and coming out. Social \& Cultural Geography 13(3): 211-231.

Lewis, N. M. 2014a. Rupture, resilience, and risk: Relationships between mental health and migration among gay-identified men in North America. Health \& Place 27: 212-219.

_. 2014b. Moving 'out' moving on: Gay men's migrations through the life course. Annals of the Association of American Geographers 104(2): 225-233.

Lewis, N. M., J. C. Gahagan, and C. Stein. 2013. Preferences for rapid point-of-care HIV testing in Nova Scotia, Canada. Sexual Health 10(2): 124-132.

Liau, A., G. Millett, and G. Marks. 2006. Meta-analytic examination of online sex-seeking and sexual risk behavior among men who have sex with men. Sexually Transmitted Diseases 33(9): 576584.

Lima, V., K. Fernandes, B. Rachlis, E. Druyts, J. Montaner, and R. Hogg. 2009. Migration adversely affects antiretroviral adherence in a population-based cohort of HIV/AIDS patients. Social Science \& Medicine 68(6): 1044-1049.

Lovell, S.A., and M. W. Rosenberg. 2011 Community capacity amongst people living with HIV/AIDS. GeoJournal 76(2): 111121.

McLeroy, K. R., D. Bibeau, A. Steckler, and K. Glanz. An ecological perspective on health promotion programs. Health Education Quarterly 15(4): 351-377.

Montaner, J. 2011. Treatment as prevention: A double hat-trick. The Lancet 378(9787): 208-209.

Moreira, P. 2012. Backwater: Nova Scotia's economic decline. Halifax, NS: Nimbus Publishing.

Moore, O. 2011. Halifax exhibition looks at gay subculture at sea in the 50s and 60s. Globe and Mail, May 30. http://www. theglobeandmail.com/arts/halifax-exhibition-looks-at-gaysubculture-at-sea-in-50s-and-60s/article581389.

Morrill, R., J. Cromartie, and G. Hart. 1999. Metropolitan, urban, and rural commuting areas: Toward a better depiction of the United States settlement system. Urban Geography 20(8): 727-748.

NSHPP (Nova Scotia Health Promotion and Protection). 2010. Notifiable diseases in Nova Scotia 2009 surveillance report. Halifax, NS: Government of Nova Scotia.

—. 2009. Notifiable diseases in Nova Scotia 2008 surveillance report. Halifax, NS: Government of Nova Scotia.

NSHW (Nova Scotia Health and Wellness). 2013. Notifiable diseases in Nova Scotia 2012 surveillance report. Halifax, NS: Government of Nova Scotia.

—. 2012. Notifiable diseases in Nova Scotia 2011 surveillance report. Halifax, NS: Government of Nova Scotia.

— 2011. Notifiable diseases in Nova Scotia 2010 surveillance report. Halifax, NS: Government of Nova Scotia.

Plumb, D. 2005. Grassroots response to HIV/AIDS in Nova Scotia. In HIV/AIDS education for adults: New directions for adult and continuing educations, ed. P. Egan. Number 105. Mississauga, Ontario: Wiley Publications 65-73.

Ryan, B. 1998. Rural Newfoundland no longer "Canada's AIDS capital." Canadian Medical Association Journal 158(8): 10051006.

Stall, R., T. C. Mills, J. Williamson, T. Hart, G. Greenwood, J. Paul, L. Pollack, D. Binson, D. Osmond, and J. A. Catania. 2003. 
Association of co-occurring psychosocial health problems and increased vulnerability to HIV/AIDS among urban men who have sex with men. American Journal of Public Health 93(6): 939-942.

Statistics Canada. 2011. Census subdivision of Halifax, Nova Scotia-RGM. Focus on Geography Series. http://www12. statcan.gc.ca/census-recensement/2011/as-sa/fogs-spg/Factscsd-eng.cfm? Lang $=$ eng\&GK $=\mathrm{CSD} \& \mathrm{GC}=1209034$.

Tomblin, S. 1995. Ottawa and the outer provinces: The challenge of regional integration in Canada. Toronto: James Lorimer \& Company.

Williams, M. L., A. M. Bowen, and K. J. Horvath. 2005. The social/ sexual environment of gay men residing in a rural frontier state: Implications for the development of HIV prevention programs. The Journal of Rural Health 21(1): 48-55.

Winett, L., S. M. Harvey, M. Branch, A. Torres, and D. Hudson. 2011. Immigrant Latino men in rural communities in the Northwest: Social environment and HIV/STI risk. Culture, Health \& Sexuality 13(6): 643-656.

Witte, B. Year in review. 2004. The Coast, Dec. 23.

Yin, K. 2003. Case study research design and method. Newbury Park, CA: Sage.

Zablotska, I., M. Holt, and G. Prestage. 2011. Changes in gay men's participation in gay community life: Implications for HIV surveillance and research. AIDS and Behaviour 16(3): 669675 . 